\title{
Atomic Scale Investigation of Orthopyroxene and Olivine Grain Boundaries by Atom Probe Tomography
}

\author{
Mukesh Bachhav ${ }^{1}$, Yan Dong ${ }^{1}$, Philip Skemer ${ }^{2}$, Emmanuelle A. Marquis ${ }^{1}$ \\ ${ }^{1}$ Department of Materials Science and Engineering, University of Michigan, Ann Arbor, MI 48109, \\ United States \\ ${ }^{2}$ Department of Earth and Planetary Sciences, Washington University, One Brookings Drive, Saint \\ Louis, Missouri, 63130, United States
}

Olivine $\left(\mathrm{Mg}_{1.8} \mathrm{Fe}_{0.2}\right) \mathrm{SiO}_{4}$ and orthopyroxene $\left(\mathrm{Mg}_{0.9} \mathrm{Fe}_{0.1}\right) \mathrm{SiO}_{3}$ are the most abundant minerals in Earth's upper mantle and represent important geochemical reservoirs in Earth. In addition, the rheological properties of these two minerals exert first order control on mantle convection and the dynamics of Earth's tectonic plates [1,2]. Both olivine and orthopyroxene have nominal compositions that include $\mathrm{Mg}, \mathrm{Fe}, \mathrm{Si}$, and $\mathrm{O}$. However due to extensive solubility of non-stoichiometric elements, both minerals may contain a number of impurities, including $\mathrm{Ca}, \mathrm{Al}, \mathrm{Mn}, \mathrm{Cr}$. During deformation, dynamic recrystallization generates new grain-boundaries, which then migrate due to differences in dislocation strain energy between adjacent grains. It has been shown that this grain boundary migration will cause impurities to become segregated along new grain boundaries. Thus, grain boundaries may represent important additional geochemical reservoirs in Earth.

Accurate chemical analyses at grain boundaries using standard microscopic techniques are challenging, especially for poor conducting geological samples [3] . Atom probe tomography (APT) is unique technique to elucidate chemistry and 3-D distribution of elements from sample at nanometer length scale. With advances in laser and sample preparation techniques in last decade, APT is now successfully applied to wide range of insulating materials like metal oxides, ceramics, and more recently biological minerals [4]. Site-specific specimens for APT were prepared from experimentally recrystallized orthopyroxene and olivine using a dual beam focused ion beam (FIB) lift-out technique.

Analyses were performed in laser mode with laser energy of $50 \mathrm{pJ} / \mathrm{pulse}$, repetition rate of $200 \mathrm{kHz}$ and detection rate of $1 \%$. 3D distribution of $\mathrm{Fe}, \mathrm{Al}$, and $\mathrm{Ca}$ is shown in Figure 1 for both phases; a 1D distribution profile across grain boundary for $\mathrm{Mg}, \mathrm{Si}$, and $\mathrm{O}$ along with several low-abundance impurities is shown in Figure 2. It is clear from figure 2, that orthopyroxene shows extensive segregation of $\mathrm{Fe}, \mathrm{Al}$ and $\mathrm{Ca}$ along with a depletion of $\mathrm{Mg}, \mathrm{Si}$ and $\mathrm{O}$ at grain boundary. Similar segregation of impurities is observed at grain boundary for olivine phase with no significant change in composition for $\mathrm{Mg}$, Si and $\mathrm{O}$. The effective grain boundary width is determined to be $\sim 4 \mathrm{~nm}$, which is a factor of two more narrow than detected using other microscopic techniques.

These results are instrumental in understanding the geochemistry of the mantle, and may have a significant impact on deformation, recrystallization, and microstructural evolution.

\section{References:}

[1] G. Hirth, D. Kohlstedt, Rheology of the Upper Mantle and the Mantle Wedge: A View from the Experimentalists, in: Inside the Subduction Factory, American Geophysical Union, 2013, pp. 83-105.

[2] S.-I. KARATO, P. Wu, Science, 260 (1993) 771-778.

[3] T. Hiraga, I.M. Anderson, D.L. Kohlstedt, Nature, 427 (2004) 699-703.

[4] M.N. Bachhav, S.-R. Chang, A. McFarland, E.A. Marquis, B. Clarkson, Microscopy and Microanalysis, 19 (2013) 184185. 


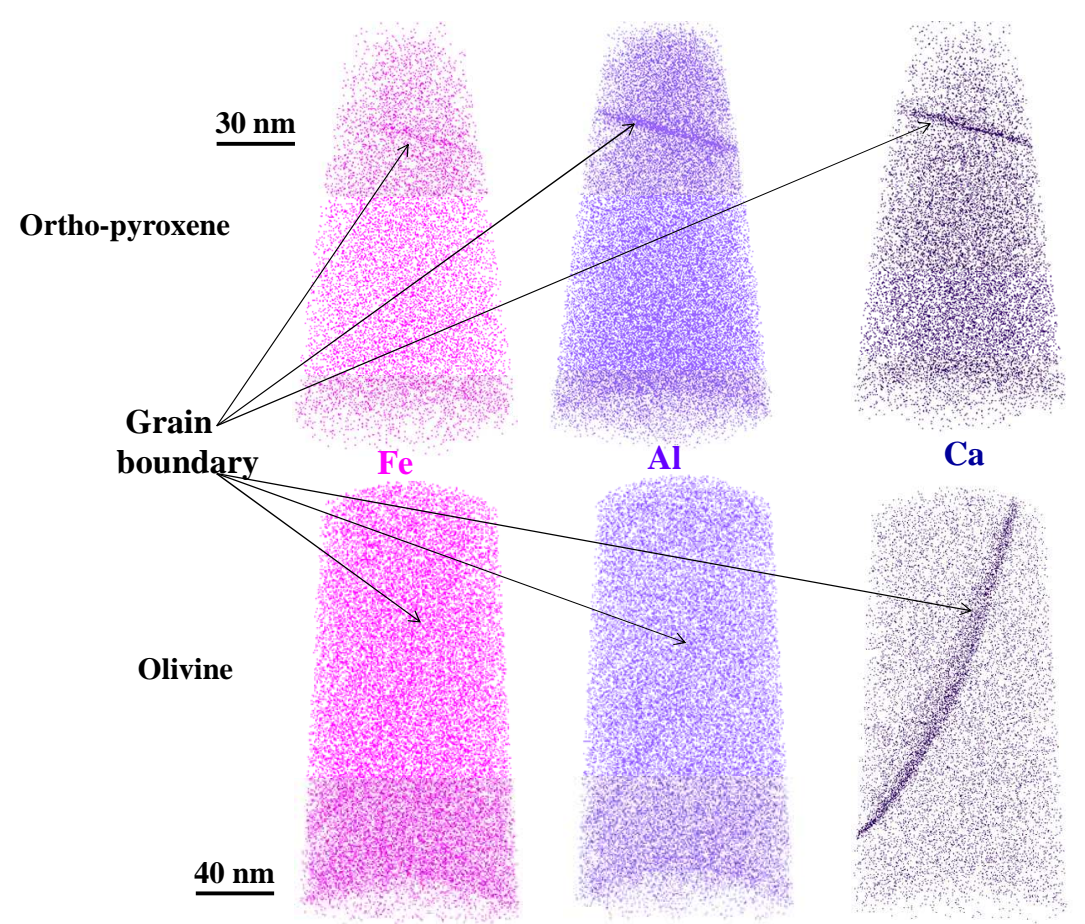

Figure 1: 3D distribution of $\mathrm{Fe}, \mathrm{Al}, \mathrm{Ca}$ in orthopyroxene and olivine samples at grain boundaries.
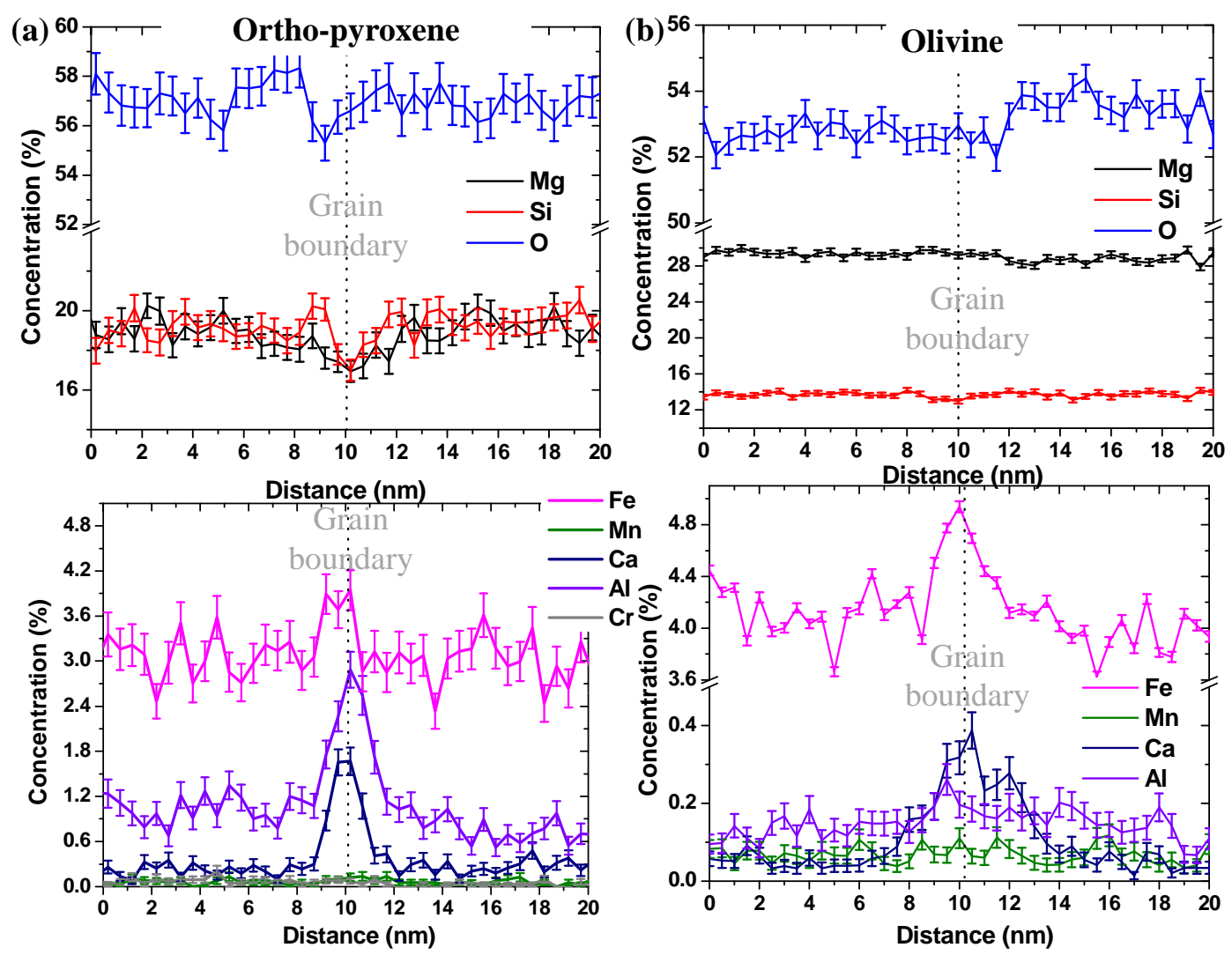

Figure 2: 1D distribution profile of $\mathrm{Mg}, \mathrm{Si}, \mathrm{O}, \mathrm{Fe}, \mathrm{Ca}, \mathrm{Mn}, \mathrm{Al}, \mathrm{Cr}$ along grain boundary for (a) Orthopyroxene and (b) Olivine. 